
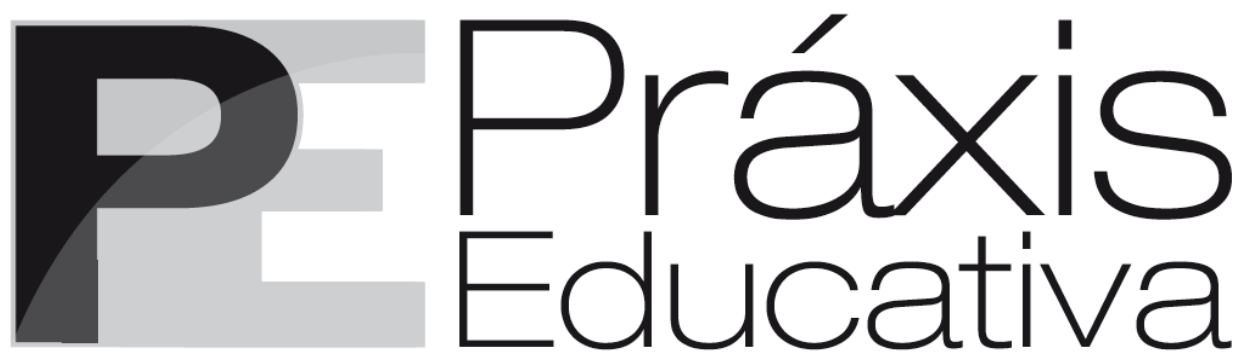

ISSN 1809-4309 (Versão online) DOI: 10.5212/PraxEduc.v.12i2.0016

\title{
Educação Física Escolar e Inclusão: uma revisão sistemática da produção discente na Pós-Graduação brasileira ${ }^{*}$
}

\section{Physical Education in school and Inclusion: a systematic review of student production in Brazilian Postgraduate studies}

\section{Educación Física Escolar e Inclusión: una revisión sistemática de la producción de los estudiantes de Posgrado en Brasil}

\author{
Patrícia Santos de Oliveira** \\ João Paulo da Silva Nunes \\ Mey de Abreu van Munster
}

Resumo: O objetivo deste estudo foi mapear e analisar a produção discente envolvendo a temática Educação Física e Inclusão, a partir de teses e dissertações oriundas dos programas de Pós-Graduação no Brasil. Trata-se de uma pesquisa exploratória do tipo revisão sistemática de literatura. Foi encontrado um total de 73 estudos, sendo 60 dissertações de Mestrado e 13 teses de Doutorado, defendidas em 33 universidades brasileiras, no período compreendido entre 2002 e 2015. Os trabalhos analisados foram organizados em 10 categorias temáticas. Verificou-se que as pesquisas têm sido centradas no processo de formação do professor de Educação Física e na atuação desse profissional. Embora o número de publicações venha crescendo nos últimos anos, é necessário descentralizar os temas de pesquisa estudados, a fim de adotar uma visão sistêmica e subsidiar ações que deem suporte a novas formas de se pensar a Inclusão no contexto da Educação Física Escolar no Brasil.

Palavras-chave: Educação Física Escolar. Educação Inclusiva. Produção científica.

\begin{abstract}
The objective of this study was to map out and analyze students' production involving the Physical Education and Inclusion theme, from theses and dissertations coming from Postgraduate programs in Brazil. It is an exploratory research of the literature systematic review type. We found 73 studies in total - 60 masters theses and 13 doctorate dissertations, defended in 33 Brazilian universities from 2002 to 2015 . The analyzed studies were organized into 10 thematic categories. We verified that the researches have concentrated on the educational process of the P.E teacher. Although the number of publications has been growing in recent years, it is necessary to decentralize the studied research themes,

\footnotetext{
* Apoio: Conselho Nacional de Desenvolvimento Científico e Tecnológico (CNPq).

** Doutoranda no Programa de Pós-Graduação em Educação Especial da Universidade Federal de São Carlos (UFScar). Email: <patriciagorup@gmail.com>.

*** Licenciado em Educação Física pela Universidade Federal de São Carlos (UFSCar). E-mail: $<$ joaopaulosilvanunes@gmail.com>.

**** Professora do Departamento de Educação Física e Motricidade Humana da Universidade Federal de São Carlos (UFSCar).E-mail: <munster.mey@gmail.com>.
} 
in order to adopt a systemic view and provide actions that give support to new ways of thinking about inclusion in the context of Physical Education in schools in Brazil.

Keywords: Physical Education in school. Inclusive education. Scientific production.

Resumen: El objetivo de este estudio fue presentar una visión general y analizar la producción de los estudiantes acerca del tema de la Educación Física e Inclusión, a partir de tesis y disertaciones oriundas de los programas de Posgrado brasileños. Se trata de una investigación exploratoria a través de revisión sistemática de la literatura. Fueron encontrados un total de 73 estudios, siendo 60 disertaciones de maestría y 13 tesis de doctorado, defendidas en 33 universidades brasileñas, entre los años 2002 y 2015. Los trabajos analizados fueron organizados en 10 categorías temáticas. Se comprobó que las investigaciones se han centrado en la formación del profesor de Educación Física y en la actuación de ese profesional. Aunque el número de publicaciones esté creciendo en los últimos años, es necesario descentralizar los temas de investigación estudiados, con el fin de adoptar una visión sistémica y apoyar acciones que respalden a los nuevos modos de pensar acerca de la inclusión en el contexto de la Educación Física en Brasil.

Palabras-clave: Educación Física Escolar. Educación Inclusiva. Producción Científica.

\section{Introdução}

A partir da década de 1990, as pesquisas referentes à temática da Inclusão escolar têm se expandido significativamente no Brasil. Para Mendes (2008), o aumento da produção acadêmica na área pode fornecer uma falsa impressão de que a Inclusão esteja ocorrendo de forma satisfatória, portanto é importante que tais pesquisas não apenas sejam ampliadas, mas também procurem responder às demandas reais desse processo.

Nunes, Ferreira e Mendes (2004) realizaram um estudo com o objetivo de analisar a produção discente nos programas de Pós-Graduação em Educação e Psicologia sobre o públicoalvo da Educação Especial. Os autores concluíram, a partir da análise do referencial teórico de tais trabalhos, que poucos estudos se baseiam nos conhecimentos produzidos em teses e dissertações anteriormente defendidas. Assim, em grande parte das pesquisas analisadas, os conhecimentos produzidos anteriormente não eram levados em consideração no momento da construção do corpo teórico de novas pesquisas.

Diante do exposto, os autores indicaram a necessidade de tornar tais produções mais acessíveis para que os pesquisadores possam utilizar o corpo de conhecimento já produzido como embasamento de seus estudos, a fim de encontrar brechas nessa produção, e, assim, propor objetivos de pesquisa que permitam avançar o conhecimento sobre o tema (NUNES; FERREIRA; MENDES, 2004).

De acordo com James, Lierberman e Ludwa (2004), o impacto da política de Inclusão na Educação Física escolar tem sido discutido amplamente pela literatura da área. Nessa direção, os estudos bibliográficos sobre a produção acadêmica têm sido cada vez mais frequentes. Mahl e Munster (2015) realizaram um estudo com o objetivo de analisar a produção discente (dissertações e teses) do Programa de Pós-Graduação em Educação Especial (PPGEEs) da Universidade Federal de São Carlos (UFSCar) na interface da Educação Física e da Educação Especial.

Sacardo (2006) realizou uma pesquisa de revisão de literatura a fim de identificar a produção em termos de teses e de dissertações em relação à temática Educação Física e Educação Especial, abrangendo estudos além do contexto escolar. A autora identificou um total de 73 teses

Práxis Educativa, Ponta Grossa, v. 12, n. 2, p. 570-590, maio/ago. 2017 Disponível em: <http://www.revistas2.uepg.br/index.php/praxiseducativa $>$ 
e dissertações produzidas somente em programas de Pós-Graduação em Educação Física e Educação Especial. Contudo, ainda não foram realizados estudos de revisão sistemática da literatura abrangendo a produção discente nos diferentes programas de Pós-Graduação do Brasil sobre a temática Educação Física e Inclusão escolar.

A grande quantidade de informações científicas produzidas e disponíveis na área da Educação Inclusiva como um todo, mais especificamente sobre o processo de Inclusão de crianças Público-alvo da Educação Especial (PAEE) ${ }^{1}$ no contexto da Educação Física escolar, conduz à necessidade de síntese dos conteúdos já produzidos, visando identificar lacunas e sobreposições na produção do conhecimento científico e, consequentemente, definir novos contornos nas pesquisas relacionadas à temática Educação Física e Inclusão Escolar.

O objetivo da presente pesquisa foi, dessa forma, mapear e analisar a produção discente sobre a temática Educação Física e Inclusão escolar a partir de teses e dissertações oriundas dos programas de Pós-Graduação do Brasil. Como objetivo específico, pretendeu-se identificar o lócus de produção, o público-alvo das pesquisas e os principais temas pesquisados.

\section{Método}

\section{- Caracterização da pesquisa}

O presente estudo caracteriza-se como uma pesquisa descritiva de revisão sistemática da literatura, do tipo integrativa (GOMES; CAMINHA, 2014). A revisão sistemática do tipo integrativa tem a finalidade de "[...] sintetizar resultados obtidos em pesquisas sobre um tema ou questão, de maneira sistemática, ordenada e abrangente. É denominada integrativa porque fornece informações mais amplas sobre um assunto/problema, constituindo, assim, um corpo de conhecimento" (ERCOLE; MELO; ALCOFORADO, 2014, p. 9.).

\section{- Procedimentos de coleta de dados}

O levantamento do material bibliográfico foi realizado junto ao Banco de Teses online da Coordenadoria de Aperfeiçoamento de Pessoal de Nível Superior (CAPES) e no portal da Biblioteca Digital de Teses e Dissertações (BDTD) do Instituto Brasileiro de Informação em Ciência e Tecnologia (IBICT). O banco e o portal foram criados com a finalidade de facilitar o acesso online às teses e às dissertações defendidas junto aos programas de Pós-Graduação do Brasil.

A investigação foi realizada em dezembro de 2015 e atualizada em julho de 2016, tendo sido utilizada a seguinte expressão de busca: "educação física" and "inclusão". O levantamento foi realizado sem delimitação de data.

\section{- Procedimento de busca, identificação e seleção dos trabalhos}

\footnotetext{
${ }^{1}$ Público-alvo da Educação Especial (PAEE): I - Alunos com deficiência física, intelectual ou sensorial. II - Alunos com transtornos globais do desenvolvimento. Incluem-se nessa definição alunos com autismo clássico, síndrome de Asperger, síndrome de Rett, transtorno desintegrativo da infância (psicoses) e transtornos invasivos sem outra especificação e III - Alunos com altas habilidades/superdotação (BRASIL, 2009).
} 
A seleção, a identificação e a avaliação dos trabalhos incluídos na revisão foram realizadas por dois pesquisadores, de forma independente, a fim de garantir fidedignidade ao estudo. Em cada etapa, foram realizadas reuniões de consenso entre os dois pesquisadores, momento que foram cruzados os dados encontrados por ambos, visando identificar possíveis discordâncias. Os trabalhos que não obtinham consenso de permanência entre os dois pesquisadores foram submetidos ao crivo de um terceiro pesquisador.

O processo de busca, identificação e seleção dos trabalhos foi realizado em quatro etapas:

- Etapa 1 - Busca e seleção: na primeira etapa todos os trabalhos localizados foram organizados em uma listagem, totalizando 231 trabalhos, tendo sido 154 extraídos do BDTD e 77 do Banco de Teses da CAPES.

- Etapa 2 - Eliminação dos trabalhos duplicados: foram comparados os títulos dos trabalhos encontrados nas duas bases de dados, verificando-se 18 títulos duplicados, os quais foram excluídos.

- Etapa 3 - Eliminação pela leitura dos títulos: foi realizada a leitura dos títulos dos 213 trabalhos, sendo excluídos aqueles que não se relacionavam ao campo específico da Educação Física ( $\mathrm{n}=110)$, restando 103 trabalhos.

- Etapa 4 - Eliminação pela leitura dos resumos ou trabalhos na íntegra: após aplicação dos critérios de inclusão e de exclusão, foram eliminados 60 trabalhos, totalizando 43 estudos pertinentes ao escopo da pesquisa.

A seleção das dissertações e das teses foi baseada nos seguintes critérios de inclusão: (a) apresentar os descritores "Educação Física" e "Inclusão" no título, resumo ou palavras-chave; (b) abordar a Inclusão no contexto da Educação Física escolar; (c) ser desenvolvida nos níveis Infantil, Fundamental e Médio da rede regular de ensino; (d) envolver o público-alvo da Educação Especial (crianças com deficiência visual, física, intelectual e auditiva; Transtorno Global do Desenvolvimento e Altas habilidades/ Superdotação).

Como critérios de exclusão, foram suprimidas as pesquisas: (a) realizadas no nível de Ensino Superior; (b) desenvolvidas no contexto das escolas ou instituições especializadas; (c) que abrangiam população não pertencente ao público-alvo da Educação Especial; (d) envolvendo Educação Física em contextos e/ou intervenções não inclusivas; (e) estudos sobre Inclusão no sentido amplo (Inclusão social/ Inclusão dos menos habilidosos).

Foram realizadas buscas manuais nas listas de referências dos trabalhos incluídos e nova busca nas bases de dados, onde foram identificadas mais 30 produções. Dessa forma, o número final de trabalhos incluídos na pesquisa de revisão totalizou 73 teses e dissertações.

A seguir será apresentado o diagrama de fluxo da informação com as diferentes fases da seleção dos estudos para a elaboração da revisão sistemática. 
Educação Física Escolar e Inclusão: uma revisão sistemática da produção discente...

Figura 1 - Diagrama de fluxo da informação com as diferentes fases de uma revisão sistemática

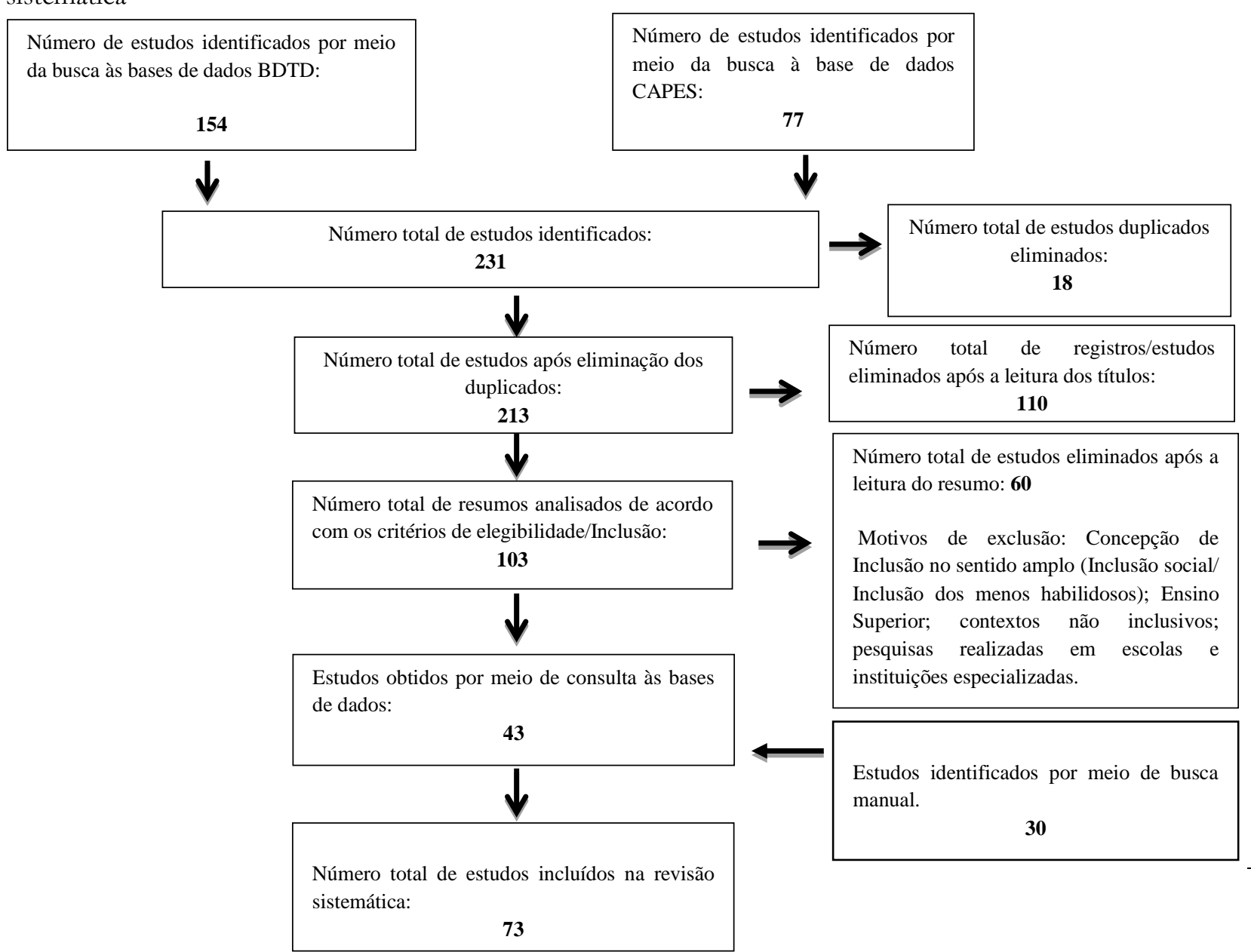

Fonte: Adaptado de Moher et al. (2009), elaborado pelos autores.

\section{Análise dos dados}

Para análise dos dados, foi utilizado o referencial teórico de análise de conteúdo proposto por Moraes (1999), o qual compreende cinco etapas, a saber: 1) preparação das informações; 2) transformação do conteúdo em unidades; 3) classificação das unidades em categorias; 4) descrição; e 5) interpretação.

Dessa forma, após leitura, os trabalhos encontrados foram organizados em um quadro a partir das seguintes informações: ano de defesa, título, autor, nível (Mestrado ou Doutorado), instituição, objetivo do estudo, aspectos metodológicos, população e principais resultados. Para o preenchimento do quadro, foram consultadas as informações disponíveis nos resumos e, quando não especificado, recorria-se à leitura da tese ou da dissertação na íntegra. Os dados numéricos foram analisados utilizando o recurso da estatística descritiva e serão apresentados, neste artigo, em gráficos. 


\section{Resultados e discussão}

Os resultados estão expostos em dois blocos: inicialmente, é apresentado um mapeamento das dissertações e das teses, com base em categorias de análise definidas à priori: origem da produção (Instituição de ensino superior/Programa); período de defesa/publicação; nível (Mestrado ou Doutorado). Posteriormente, é apresentada a análise da produção científica, em que são expostas as informações relacionadas à população foco dos estudos e os principais temas abordados pelas pesquisas.

Foi encontrado um total de 73 estudos, sendo 60 dissertações de Mestrado e 13 teses de Doutorado, defendidas em 33 universidades brasileiras no período compreendido entre 2002 e 2015. O Quadro 1 a seguir apresenta os trabalhos encontrados e incluídos na pesquisa, os quais estão organizados a partir do ano de publicação.

Quadro 1 - Relação das teses e das dissertações encontradas e incluídas na pesquisa

\begin{tabular}{|c|c|}
\hline Ano & Autor/ Título \\
\hline 2002 & $\begin{array}{l}\text { CUSTÓDIO, V. S. Atividades lúdicas como elemento facilitador para inclusão do } \\
\text { deficiente auditivo na classe comum. }\end{array}$ \\
\hline 200 & $\begin{array}{l}\text { FLORENCE, R. B. P. A educação física na rede pública do município de São João da Boa } \\
\text { Vista - SP e o portador de necessidade especiais. }\end{array}$ \\
\hline 2003 & $\begin{array}{l}\text { SOUZA, W. C. A Inclusão do educando com deficiência na Escola Pública Municipal de } \\
\text { Goiânia: o discurso dos professores de Educação Física. }\end{array}$ \\
\hline 200 & $\begin{array}{l}\text { CRUZ, G. C. Formação continuada de professores de Educação Física em ambiente } \\
\text { escolar inclusivo. }\end{array}$ \\
\hline 2005 & $\begin{array}{l}\text { GORGATTI, M. G. Educação física escolar e Inclusão: uma análise a partir do } \\
\text { desenvolvimento motor e social de adolescentes com deficiência visual e das atitudes dos } \\
\text { professores. }\end{array}$ \\
\hline 2005 & em classe regular: um estudo de caso com abordagem \\
\hline 2005 & CHICON, J. F. Inclusão na Educação Física escolar: construindo caminhos. \\
\hline 200 & $\begin{array}{l}\text { CURVO, J. P. S. A Educação Física no contexto inclusivo: análise do curso de capacitação } \\
\text { de professores multiplicadores em Educação Física Adaptada. }\end{array}$ \\
\hline 2006 & $\begin{array}{l}\text { MATTOS, L. A. Políticas públicas de formação do professor de Educação Física: sua } \\
\text { contribuição para a educação inclusiva. }\end{array}$ \\
\hline 2006 & $\begin{array}{l}\text { NEVES, C. P. A Inclusão de pessoas com deficiência segundo professores de Educação } \\
\text { Física na Secretaria Municipal de Educação de Goiânia. }\end{array}$ \\
\hline 2006 & $\begin{array}{l}\text { SEABRA JUNIOR, L. Inclusão, necessidades especiais e Educação Física: considerações } \\
\text { sobre a ação pedagógica no ambiente escolar. }\end{array}$ \\
\hline 2007 & $\begin{array}{l}\text { COSTA, S. H. Descrição das relações professor-aluno no processo de ensino inclusivo de } \\
\text { Educação Física. }\end{array}$ \\
\hline 2008 & ALMEIDA, M. S. Educação Física escolar e a Inclusão de alunos com deficiências. \\
\hline 2008 & $\begin{array}{l}\text { SOUZA, J. V. Tutoria: estratégias de ensino para Inclusão de alunos com deficiência em } \\
\text { aulas de Educação Física. }\end{array}$ \\
\hline 2009 & usão na Educação Física escolar: abrindo novas trilhas. \\
\hline
\end{tabular}


Educação Física Escolar e Inclusão: uma revisão sistemática da produção discente...

\begin{tabular}{|c|c|}
\hline 2009 & $\begin{array}{l}\text { RAÚJO, L. A. S. Programa de desenvolvimento de competências para profissionais de } \\
\text { lucação Física na educação de crianças com deficiência intelectual. }\end{array}$ \\
\hline 2009 & $\begin{array}{l}\text { DNATO, N. A. M. Inclusão escolar: um estudo da formação continuada dos professor } \\
\text { Educação Física na cidade de Araraquara-SP. }\end{array}$ \\
\hline 20 & $\begin{array}{l}\text { NÇALVES, G. C. Dos saberes } \\
\text { ticas inclusivas para alunos com }\end{array}$ \\
\hline 2009 & $\begin{array}{l}\text { LIVEIRA, M. F. L. Sentidos constituídos por professores } \\
\text { ocesso de Inclusão de alunos com deficiência: um estudo e }\end{array}$ \\
\hline 2009 & NA, L. D. As ilusões do paradigma da Inclusão na pr \\
\hline 2009 & $\begin{array}{l}\text { LERNO, M. B. Interação entre alunos com e sem deficiência na Educação Física } \\
\text { colar: validação de instrumento. }\end{array}$ \\
\hline 200 & $\begin{array}{l}\text { INCHES JUNIOR, M. } \\
\text { unicipal de Hortolândia }\end{array}$ \\
\hline 2010 & $\begin{array}{l}\text { EZERRA, A. F. S. Estratégias para o ensino inclusivo de alunos com deficiência nas } \\
\text { las de Educação Física. }\end{array}$ \\
\hline 201 & entes \\
\hline 201 & $\begin{array}{l}\text { RLANDO, P. A. O colega tutor de alunos com deficiência } \\
\text { ica. }\end{array}$ \\
\hline 201 & $\begin{array}{l}\text { ISSI, S. O ambiente e a acessibilidade na escola e nas aulas de Educação Física: a } \\
\text { erspectiva de uma aluna com deficiência visual. }\end{array}$ \\
\hline 2011 & $\begin{array}{l}\text { UARTE, L. C. Ação pedagógica de professores de Educação Física em turmas } \\
\text { nclusivas. }\end{array}$ \\
\hline 2011 & $\begin{array}{l}\text { FILUS, J. F. Amarrações e arrumações na Inclusão escolar do município de Hortolândia- } \\
\text { SP. }\end{array}$ \\
\hline 2011 & $\begin{array}{l}\text { NI, M. L. S. } \\
\text { ficiência. }\end{array}$ \\
\hline 2011 & $\begin{array}{l}\text { RANCISCO, A. B. Educação Física escolar para alunos com deficiência incluídos na rede } \\
\text { tadual de ensino em São Paulo. }\end{array}$ \\
\hline 2011 & $\begin{array}{l}\text { OMES, D. P. Os sentidos da Inclusão de alunos com deficiência no discurso dos } \\
\text { ofessores de Educação Física. }\end{array}$ \\
\hline 2011 & $\begin{array}{l}\text { LOPES, A. C. A interação entre alunos e professor na classe da } 3^{a} \text { série do Ensino } \\
\text { Fundamental em sala inclusiva: um estudo exploratório. }\end{array}$ \\
\hline 2011 & $\begin{array}{l}\text { MIRON, E. M. Da pedagogia do jogo ao voleibol sentado: possibilidades inclusivas na } \\
\text { Educação Física escolar. }\end{array}$ \\
\hline 2011 & NUNES, D. M. Educação física, infância e Inclusão: aproximações à prática docente. \\
\hline 2011 & $\begin{array}{l}\text { QUEIRA, M. F. Educação física, autismo e Inclusão: ressignificando a prática } \\
\text { dagógica. }\end{array}$ \\
\hline 2011 & $\begin{array}{l}\text { SOUZA, G. C. Reorientação didático-pedagógica da Educação Física na perspectiva da } \\
\text { Inclusão escolar. }\end{array}$ \\
\hline 2011 & $\begin{array}{l}\text { VALVERDE, G. S. A docência em Educação Física: atuação em meio inclusivo de } \\
\text { professores ex-atletas e não atletas. }\end{array}$ \\
\hline 2012 & FREITAS, C. Mudança de atitudes sobre Inclusão em professores de Educação Física na \\
\hline
\end{tabular}

Práxis Educativa, Ponta Grossa, v. 12, n. 2, p. 570-590, maio/ago. 2017 Disponível em: <http://www.revistas2.uepg.br/index.php/praxiseducativa > 


\begin{tabular}{|c|c|}
\hline & \\
\hline 2012 & $\begin{array}{l}\text { GOMES, A. E. G. Inclusão de alunos com deficiência nas aulas de Educação Física } \\
\text { escolar em escolas públicas municipais de Fortaleza (CE). }\end{array}$ \\
\hline 2012 & $\begin{array}{l}\text { AHL, E. Práticas pedagógicas dos professores de Educação Física frente a [sic] inclusão } \\
\text { e alunos com deficiência. }\end{array}$ \\
\hline 2012 & $\begin{array}{l}\text { NASCIMENTO, S. F. Formação continuada de professores de Educação Física na } \\
\text { perspectiva da Inclusão. }\end{array}$ \\
\hline 2012 & $\begin{array}{l}\text { NTO, T. M. G. Inclusão nas aulas de Educação Física: reflexões a partir da prática } \\
\text { dagógica de um professor iniciante. }\end{array}$ \\
\hline 2012 & SEABRA JUNIOR, L. Educação Física e Inclusão educa \\
\hline 2012 & $\begin{array}{l}\text { SILVA, O. O. N. Os desafios c } \\
\text { regular: mapeando a realidade d }\end{array}$ \\
\hline 2013 & $\begin{array}{l}\text { BATALIOTTI, S. E. Portal do professor e Educação Física adaptada: sugestões para a } \\
\text { prática docente inclusiva. }\end{array}$ \\
\hline 2013 & 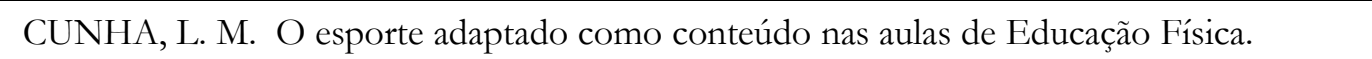 \\
\hline 2013 & $\begin{array}{l}\text { MARQUES, A. E. Rodas de conversa: uma proposta para aprimorar a prática docente em } \\
\text { Educação Física escolar. }\end{array}$ \\
\hline 2013 & $\begin{array}{l}\text { SOUZA, F. A. Formação, Educação Física e Inclusão: compreendendo os processos } \\
\text { inclusivos. }\end{array}$ \\
\hline 2013 & $\begin{array}{l}\text { ALVES, M. L. T. O aluno com deficiência visual nas aulas de Educação Física: análise do } \\
\text { processo inclusivo. }\end{array}$ \\
\hline 2013 & WEBER, J. M. O. Avaliação em Educação \\
\hline 2013 & $\begin{array}{l}\text { OLIVEIRA, V. C. Educação Física e deficiência intelectual: prática pedagógica para a } \\
\text { Inclusão escolar. }\end{array}$ \\
\hline 2013 & $\begin{array}{l}\text { CARVALHO, P. C. O. A importância da psicomotricidade nas aulas de Educação Física } \\
\text { para estudantes com deficiência físico-motora. }\end{array}$ \\
\hline 2013 & $\begin{array}{l}\text { CATALDI, C. L. Os caminhos percorridos pela } \\
\text { partir do perfil e propostas pedagógicas dos prof }\end{array}$ \\
\hline 2013 & $\begin{array}{l}\text { CMEIDA, N. S. Surdo, língua e cultura: as práticas esportivas, recreativas e corporais na } \\
\text { ucação inclusiva. }\end{array}$ \\
\hline 201 & $\begin{array}{l}\text { CARVALHO, C. L. Conteúdo da Educação Física e a pedagogia de Freinet: pintando uma } \\
\text { possibilidade para o aluno com Síndrome de Down. }\end{array}$ \\
\hline 2014 & $\begin{array}{l}\text { DISTEFANO, F. Educação Física e Inclusão esco } \\
\text { de Educação e a matriz curricular de Educação Físic }\end{array}$ \\
\hline 2014 & $\begin{array}{l}\text { TEBALDI, M. Formação continuada em Educação Física e Inclusão do deficiente no } \\
\text { ensino regular sob a ótica de professores. }\end{array}$ \\
\hline 2014 & $\begin{array}{l}\text { JUNIOR, J. C. C. A proposta curricular do estado de São Paulo: Educação Física e a } \\
\text { educação inclusiva. }\end{array}$ \\
\hline 2014 & $\begin{array}{l}\text { SCHNEIDER, R. Inclusão e exclusão em aulas de Educação Física no } 1^{\circ} \text { ano do Ensino } \\
\text { Fundamental no colégio Pedro II. }\end{array}$ \\
\hline 2014 & $\begin{array}{l}\text { OLIVEIRA, V. M. Ensino Colaborativo e Educação Física: Contribuições à Inclusão } \\
\text { Escolar. }\end{array}$ \\
\hline 2014 & Iunos com deficiencia no Ensino Medio: analise da p \\
\hline
\end{tabular}


Educação Física Escolar e Inclusão: uma revisão sistemática da produção discente...

\begin{tabular}{|l|l|}
\hline 2014 & pedagógica na Educação Física. \\
\hline 2015 & $\begin{array}{l}\text { ANDRADE, J. M. A. Inclusão Escolar: modos de participação de alunos e professores nas } \\
\text { aulas de Educação Física. }\end{array}$ \\
\hline 2015 & $\begin{array}{l}\text { FIORINI, M. L. S. Formação continuada do professor de Educação Física em tecnologia } \\
\text { assistiva visando a Inclusão. }\end{array}$ \\
\hline 2015 & $\begin{array}{l}\text { TOLOI, G. G. Formação de professores de Educação Física para Inclusão educacional } \\
\text { usando tecnologia assistiva. }\end{array}$ \\
\hline 2015 & $\begin{array}{l}\text { SANOES, A. S. Educação Física na perspectiva inclusiva: um estudo em uma escola do } \\
\text { Fecife. S. B. Cartilha educativa sobre perda auditiva para professores de Educação }\end{array}$ \\
\hline 2015 & $\begin{array}{l}\text { TEO, G. H. Adaptações na Educação Física escolar: intervenções de professores para um } \\
\text { currículo acessível aos estudantes com deficiência. }\end{array}$ \\
\hline 2015 & $\begin{array}{l}\text { QUEDAS, C. L. R. O transtorno do espectro do Autismo e a Educação Física escolar: a } \\
\text { prática do profissional da rede estadual de São Paulo. }\end{array}$ \\
\hline 2015 & $\begin{array}{l}\text { COSTA, C. M. Inclusão de estudantes com deficiência visual nas aulas de Educação Física: } \\
\text { um estudo de caso. }\end{array}$ \\
\hline 2015 & $\begin{array}{l}\text { COSMO, J. Tecendo olhares sobre a Educação Física e a Inclusão: um estudo sobre a } \\
\text { subjetividade do trabalho docente em contexto de formação continuada. }\end{array}$ \\
\hline 2015 & $\begin{array}{l}\text { SIQUARA, Z. O. Estética Marxiana e formação humana: inspirações para a Educação } \\
\text { Física escolar e Inclusão. }\end{array}$ \\
\hline 2015 & $\begin{array}{l}\text { CUNHA, R. F. P. Educação Física escolar: concepções e princípios sobre Inclusão escolar } \\
\text { de professores da Rede Municipal de Fortaleza. }\end{array}$ \\
\hline 2015 & $\begin{array}{l}\text { CARVALHO, A. F. Professores do ensino infantil, práticas corporais e a Inclusão de } \\
\text { crianças com necessidades especiais em um município do estado do Tocantins. }\end{array}$ \\
\hline
\end{tabular}

Fonte: Dados da pesquisa, elaborado pelos autores.

\section{- Origem das dissertações e das teses}

As produções discentes são oriundas de 33 instituições de Ensino Superior (IES) (Quadro 2), sendo 22 públicas e 11 privadas. Em relação à distribuição geográfica das IES, 61\% estão localizadas na região Sudeste, $24 \%$ na região Sul, $9 \%$ na região Nordeste do Brasil e $6 \%$ na região Centro-Oeste.

Quadro 2 - Lócus de produção - Origem das dissertações e das teses

\begin{tabular}{|l|l|c|c|c|l|l|}
\multicolumn{1}{|c|}{ Instituição } & $\begin{array}{c}\text { Programa de } \\
\text { Pós-Graduação }\end{array}$ & Dissertações & Teses & Total & $\begin{array}{c}\text { Natureza } \\
\text { administrativa }\end{array}$ & Estado \\
\hline $\begin{array}{l}\text { Universidade Estadual de } \\
\text { Campinas - UNICAMP }\end{array}$ & Educação Física & 6 & 4 & 10 & Pública & SP \\
\hline $\begin{array}{l}\text { Universidade Federal de São } \\
\text { Carlos - UFSCar }\end{array}$ & $\begin{array}{l}\text { Educação } \\
\text { Especial }\end{array}$ & 6 & 2 & 8 & Pública & SP \\
\hline Universidade Federal do & Educação Física & 8 & 0 & 8 & Pública & ES \\
\hline
\end{tabular}

Práxis Educativa, Ponta Grossa, v. 12, n. 2, p. 570-590, maio/ago. 2017 Disponível em: <http://www.revistas2.uepg.br/index.php/praxiseducativa > 
Patrícia Santos de Oliveira, João Paulo da Silva Nunes e Mey de Abreu van Munster

\begin{tabular}{|c|c|c|c|c|c|c|}
\hline \multicolumn{7}{|l|}{ Espírito Santo - UFES } \\
\hline $\begin{array}{l}\text { Universidade Estadual de } \\
\text { São Paulo UNESP- Marília }\end{array}$ & Educação & 2 & 3 & 5 & Pública & SP \\
\hline $\begin{array}{l}\text { Universidade Presbiteriana } \\
\text { Mackenzie }\end{array}$ & $\begin{array}{l}\text { Distúrbios do } \\
\text { movimento }\end{array}$ & 3 & 1 & 4 & Particular & $\mathrm{SP}$ \\
\hline $\begin{array}{l}\text { Universidade Federal da } \\
\text { Bahia - UFBA }\end{array}$ & Educação & 3 & 0 & 3 & Pública & $\mathrm{BA}$ \\
\hline \multirow{2}{*}{$\begin{array}{l}\text { Universidade Federal de } \\
\text { Santa Catarina - UFSC }\end{array}$} & Psicologia & 1 & 0 & \multirow[t]{2}{*}{2} & \multirow[t]{2}{*}{ Pública } & \multirow[t]{2}{*}{ SC } \\
\hline & Educação Física & 1 & 0 & & & \\
\hline $\begin{array}{l}\text { Universidade Estadual de } \\
\text { Ponta Grossa - UEPG }\end{array}$ & Educação & 2 & 0 & 2 & Pública & PR \\
\hline $\begin{array}{l}\text { Universidade Federal de } \\
\text { Pelotas - UFPel }\end{array}$ & Educação & 2 & 0 & 2 & Pública & RS \\
\hline $\begin{array}{l}\text { Universidade Estadual de } \\
\text { Londrina - UEL }\end{array}$ & Educação & 2 & 0 & 2 & Pública & PR \\
\hline \multirow{2}{*}{$\begin{array}{l}\text { Universidade do Estado do } \\
\text { Rio de Janeiro - UERJ }\end{array}$} & Educação & 1 & 0 & \multirow[t]{2}{*}{2} & \multirow[t]{2}{*}{ Pública } & \multirow[t]{2}{*}{ RJ } \\
\hline & $\begin{array}{l}\text { Políticas públicas } \\
\text { e formação } \\
\text { humana }\end{array}$ & 1 & 0 & & & \\
\hline \multirow{2}{*}{$\begin{array}{l}\text { Universidade de São Paulo - } \\
\text { USP }\end{array}$} & Educação Física & 0 & 1 & \multirow[t]{2}{*}{2} & \multirow[t]{2}{*}{ Pública } & \multirow[t]{2}{*}{$\mathrm{SP}$} \\
\hline & Educação & 0 & 1 & & & \\
\hline \multirow{2}{*}{$\begin{array}{l}\text { Universidade Metodista de } \\
\text { Piracicaba }\end{array}$} & Educação Física & 1 & 0 & \multirow[t]{2}{*}{2} & \multirow[t]{2}{*}{ Particular } & \multirow[t]{2}{*}{ SP } \\
\hline & Educação & 1 & 0 & & & \\
\hline $\begin{array}{l}\text { Universidade Salgado de } \\
\text { Oliveira }\end{array}$ & $\begin{array}{l}\text { Ciências da } \\
\text { Atividade Física }\end{array}$ & 2 & 0 & 2 & Particular & RJ \\
\hline $\begin{array}{l}\text { Centro Universitário } \\
\text { UNIVATES }\end{array}$ & $\begin{array}{l}\text { Ambiente e } \\
\text { Desenvolviment } \\
\text { o }\end{array}$ & 1 & 0 & 1 & Particular & RS \\
\hline $\begin{array}{l}\text { Universidade Federal de } \\
\text { Viçosa -UFV }\end{array}$ & Educação Física & 1 & 0 & 1 & Pública & MG \\
\hline $\begin{array}{l}\text { Universidade Federal de Juiz } \\
\text { de Fora }\end{array}$ & Educação Física & 1 & 0 & 1 & Pública & MG \\
\hline $\begin{array}{l}\text { Universidade Federal de } \\
\text { Santa Maria }\end{array}$ & Educação & 1 & 0 & 1 & Pública & RS \\
\hline $\begin{array}{l}\text { Pontifícia Universidade } \\
\text { Católica PUC - SP }\end{array}$ & Educação & 1 & 0 & 1 & Particular & $\mathrm{SP}$ \\
\hline $\begin{array}{l}\text { Universidade Regional de } \\
\text { Blumenau - FURB }\end{array}$ & Educação & 1 & 0 & 1 & Pública & SC \\
\hline $\begin{array}{l}\text { Universidade Federal de Juiz } \\
\text { de Fora - UFJF }\end{array}$ & Educação & 1 & 0 & 1 & Pública & MG \\
\hline $\begin{array}{l}\text { Universidade Federal de } \\
\text { Uberlândia }\end{array}$ & Educação & 0 & 1 & 1 & Pública & MG \\
\hline
\end{tabular}


Educação Física Escolar e Inclusão: uma revisão sistemática da produção discente...

\begin{tabular}{|c|c|c|c|c|c|c|}
\hline $\begin{array}{l}\text { Universidade do Vale do } \\
\text { Itajaí - UNIVALI }\end{array}$ & $\begin{array}{l}\text { Saúde e gestão } \\
\text { do trabalho - } \\
\text { Mestrado } \\
\text { profissional }\end{array}$ & 1 & 0 & 1 & Particular & SC \\
\hline $\begin{array}{l}\text { Universidade Estadual de } \\
\text { São Paulo UNESP - Campus } \\
\text { Bauru }\end{array}$ & $\begin{array}{l}\text { Psicologia do } \\
\text { Desenvolviment } \\
\text { o e } \\
\text { aprendizagem }\end{array}$ & 1 & 0 & 1 & Pública & $\mathrm{SP}$ \\
\hline $\begin{array}{l}\text { Universidade Estadual de } \\
\text { São Paulo UNESP - Campus } \\
\text { Araraquara }\end{array}$ & Educação & 1 & 0 & 1 & Pública & SP \\
\hline $\begin{array}{l}\text { Universidade Estadual de } \\
\text { São Paulo UNESP - Campus } \\
\text { Rio Claro }\end{array}$ & $\begin{array}{l}\text { Ciências do } \\
\text { movimento } \\
\text { humano }\end{array}$ & 1 & 0 & 1 & Pública & $\mathrm{SP}$ \\
\hline $\begin{array}{l}\text { Universidade de } \\
\text { Pernambuco }\end{array}$ & Educação Física & 1 & 0 & 1 & Pública & $\mathrm{PE}$ \\
\hline $\begin{array}{l}\text { Universidade Federal do } \\
\text { Ceará }\end{array}$ & Educação & 1 & 0 & 1 & Pública & $\mathrm{CE}$ \\
\hline $\begin{array}{l}\text { Universidade Católica Dom } \\
\text { Bosco }\end{array}$ & Educação & 1 & 0 & 1 & Particular & MS \\
\hline $\begin{array}{l}\text { Universidade Católica de } \\
\text { Goiás }\end{array}$ & Educação & 1 & 0 & 1 & Particular & GO \\
\hline $\begin{array}{l}\text { Universidade Anhanguera de } \\
\text { São Paulo }\end{array}$ & $\begin{array}{l}\text { Reabilitação do } \\
\text { Equilíbrio } \\
\text { Corporal e } \\
\text { Inclusão Social }\end{array}$ & 1 & 0 & 1 & Particular & $\mathrm{SP}$ \\
\hline $\begin{array}{l}\text { Universidade Cidade de São } \\
\text { Paulo }\end{array}$ & Educação & 1 & 0 & 1 & Particular & SP \\
\hline $\begin{array}{l}\text { Centro Universitário Moura } \\
\text { Lacerda }\end{array}$ & Educação & 1 & 0 & 1 & Particular & $\mathrm{SP}$ \\
\hline
\end{tabular}

Fonte: Dados da pesquisa, elaborado pelos autores.

A maior parte das produções científicas na área está concentrada em quatro programas de Pós-Graduação: O Programa de Pós-Graduação em Educação Física da Universidade Estadual de Campinas (Unicamp), na linha de pesquisa em Educação Física Adaptada, o qual apresenta o maior número de publicações (seis dissertações de Mestrado e quatro teses de Doutorado); o Programa de Pós-Graduação em Educação Especial da Universidade Federal de São Carlos (UFSCar) possui oito produções: seis dissertações de Mestrado e duas teses de Doutorado); o Programa de Pós-Graduação em Educação Física da Universidade Federal do Espírito Santo integra oito dissertações defendidas; o Programa de Pós-Graduação em Educação, vinculado à Universidade Estadual Paulista (UNESP - Campus Marília), possui um total de cinco trabalhos defendidos (duas dissertações e três teses).

Sobre o lócus de produção, verificou-se uma distribuição desigual de publicações por região geográfica. A região Sudeste corresponde à maioria das produções com $72 \%$ do total, seguida da região Sul com 18\% das publicações. De acordo com Manoel e Carvalho (2011), os programas de Pós-Graduação em Educação Física concentram-se, em sua maioria, nas regiões 
Sudeste e Sul do Brasil. Assim, para os autores, um dos desafios para o sistema nacional de PósGraduação é ampliar o número de programas fora do eixo Sul/Sudeste. A seguir, o Gráfico 1 apresenta a distribuição das publicações por região geográfica.

Gráfico 1 - Distribuição das publicações por região geográfica

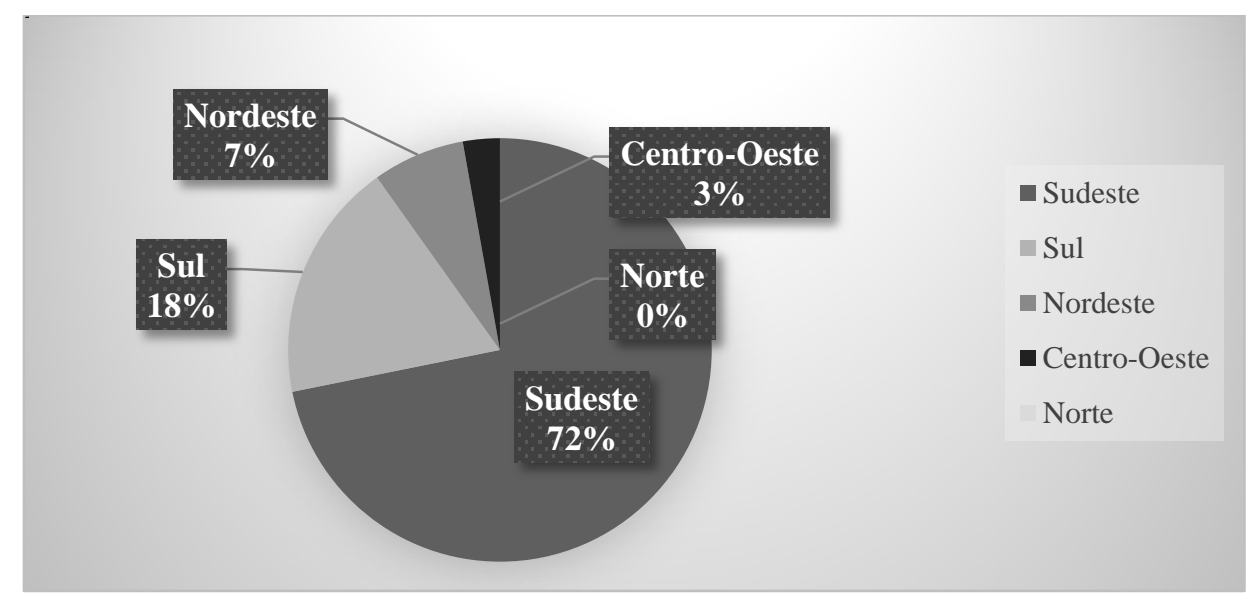

Fonte: Dados da pesquisa, elaborado pelos autores.

Dessa forma, os dados comprovam as disparidades da produção acadêmica científica brasileira, as quais não são exclusivas da área de estudo da Educação Física. Faz-se necessária, assim, a realização de políticas públicas voltadas à Pós-Graduação a fim de ampliar qualitativa e quantitativamente os programas de Mestrado e Doutorado, sobretudo na área de Educação Física, principalmente nas regiões Norte, Centro-Oeste e Nordeste, com o intuito de descentralizar a produção de conhecimento.

Enquanto 57 produções são oriundas de IES públicas, apenas 16 são derivadas de IES privadas, ou seja, as universidades públicas são responsáveis por $78 \%$ das dissertações e teses envolvendo a interface Educação Física Escolar e Inclusão. Dessa monta, os resultados evidenciam que as pesquisas direcionadas à Inclusão de crianças com deficiência no contexto das aulas de Educação Física escolar vêm sendo produzidas com maior ênfase pelas instituições públicas de Ensino Superior, localizadas, em sua maioria, na região Sudeste do país. Nunes, Ferreira e Mendes (2004) também constataram que as pesquisas com foco no público-alvo da Educação Especial são produzidas com maior ênfase pelas IES públicas.

De acordo com Steiner (2005), as universidades e os institutos públicos brasileiros lideram a maior parte dos programas de Doutorado e Mestrado acadêmicos em todas as áreas de conhecimento. Assim, é possível inferir que a maior produção por parte das IES públicas de pesquisas na área de Educação Física na perspectiva da Inclusão escolar se justifica pelo fato de que grande parte dos programas de Pós-Graduação brasileiros são de natureza administrativa pública.

No entanto, as universidades particulares possuem número crescente dentre as instituições de Mestrado intermediárias e especializadas (STEINER, 2005). Assim, constatou-se que parte das produções das universidades particulares na área de Educação Física e Inclusão de pessoas com deficiência são dissertações de Mestrado oriundas de programas mais específicos e especializados (Mestrado profissional), o que corrobora com os achados de Steiner (2005).

Os programas de Pós-Graduação em Educação Física e Educação lideram grande parte da produção na área, representando o crescente destaque que a área de estudo em questão vem 
ganhando nos últimos anos, principalmente no âmbito dos programas de Educação Física. O significativo número de publicações em programas na área de Educação pode representar a valorização atribuída às pesquisas orientadas ao campo pedagógico da Educação Física, ou, ainda, pode dar-se pelo maior número de programas na área de Educação em detrimento de programas de Pós-Graduação especificamente em Educação Física (PPGEF).

De acordo com Manoel e Carvalho (2011), grande parte dos PPGEF oferece somente a titulação de Mestre, e os programas que oferecem títulos de Doutor em Educação Física são recentes e em número reduzido. Assim, os profissionais de Educação Física que almejam a formação em nível de Doutorado acabam por buscar a formação em programas de PósGraduação orientados pelas ciências humanas, biológicas, como, por exemplo, Educação, Filosofia, Psicologia, Antropologia e História.

\section{- Ano de defesa/publicação}

No Gráfico 2 são apresentados os dados referentes à distribuição da produção acadêmica por ano de defesa/publicação.

Gráfico 2 - Distribuição da produção acadêmica por ano de defesa/publicação

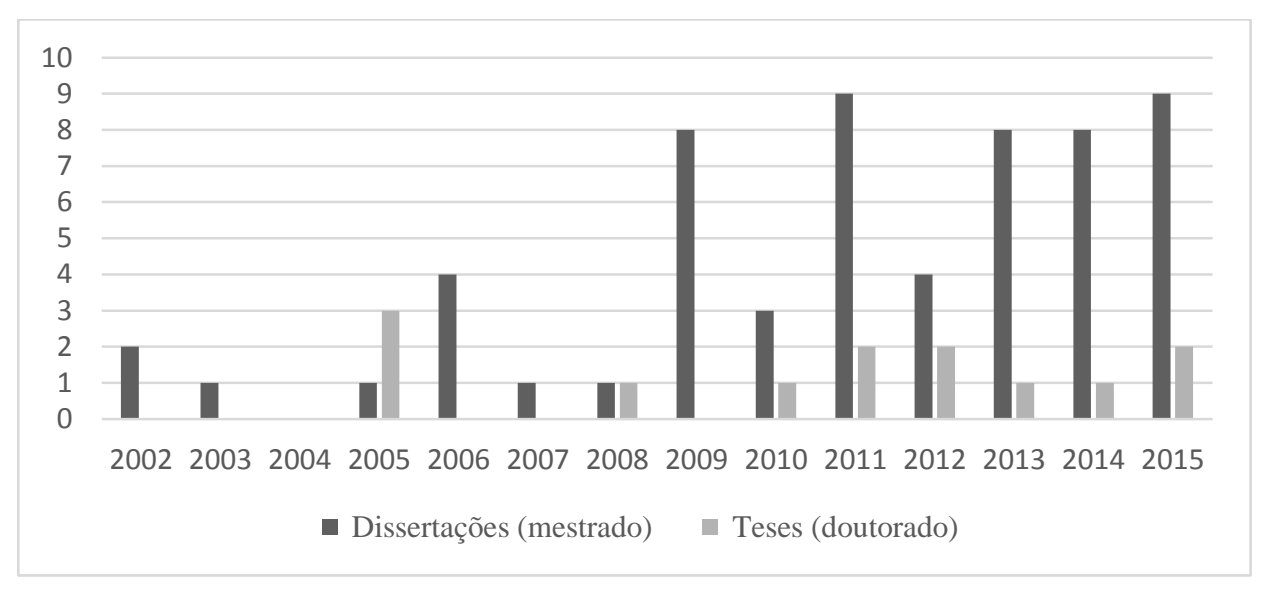

Fonte: Dados da pesquisa, elaborado pelos autores.

Foram encontrados estudos publicados entre os anos de 2002 a 2015. O ano de 2002 como marco inicial das publicações se refere ao fato de as bases de dados pesquisadas abarcarem somente as dissertações e as teses defendidas a partir do ano de 2002. As primeiras pesquisas localizadas estão vinculadas respectivamente ao Programa de Pós-Graduação em Educação Física da Unicamp e ao Programa de Pós-Graduação em Educação da Unesp- Marília.

Os resultados indicaram que houve um aumento progressivo no número de dissertações produzidas no período de 2002 a 2015. No entanto, no que se refere às teses, a produção manteve-se equilibrada, ou seja, sem alterações significativas. A menor produção em termos de teses pode indicar uma possível mudança de temática ou área de estudo pelos pesquisadores ou ainda que estes acabam não avançando para a titulação de Doutorado.

Em relação à distribuição das publicações por ano de defesa, pode-se verificar que houve um aumento expressivo nas publicações na área de Educação Física Inclusiva a partir do ano de 2009. Dados semelhantes foram encontrados na pesquisa realizada por Mahl e Munster (2015). As autoras destacaram que as primeiras pesquisas sobre Educação Física em interface com a Educação Especial, relacionadas à temática da Inclusão escolar de alunos com deficiência 
realizadas no Programa de Pós-Graduação em Educação Especial da UFSCar, surgiram a partir do quadriênio 2005-2009. Já Sacardo (2006) identificou um crescimento significativo das teses e das dissertações relacionadas à temática Educação Física e Educação Especial a partir do ano 2000. Outro ponto que pode ser destacado se refere ao aperfeiçoamento dos bancos de teses e dissertações, defendidas no Brasil, no processo de disponibilização online, facilitando o acesso às publicações e à recuperação das informações em nível nacional.

Um fator que coincide com o aumento das pesquisas relacionadas à Inclusão no contexto da Educação Física escolar refere-se à publicação de documentos oficiais como as Diretrizes Nacionais para a Educação Especial na Educação Básica (BRASIL, 2001), a Política Nacional de Educação Especial na Perspectiva da Educação Inclusiva (BRASIL, 2008), as Diretrizes Operacionais para o Atendimento Educacional Especializado na Educação Básica (BRASIL, 2009), dentre outros. Assim, pode-se inferir que a ampliação das produções científicas em Educação Física escolar com foco na Inclusão de alunos público-alvo da Educação Especial foi impulsionada, dentre outros fatores, pela adoção de novas políticas educacionais direcionadas à perspectiva da Educação Inclusiva e, consequentemente, ao crescente número de matrículas de alunos com deficiência no contexto escolar, despertando o interesse de pesquisadores pela área de estudo em questão.

\section{- Populações envolvidas no estudo}

Dos 73 estudos encontrados, seis se tratavam de pesquisas documentais de análises de dados públicos de fonte primária, três pesquisas bibliográficas e 64 se caracterizavam como estudos de campo. O Gráfico 4 apresenta os 64 estudos distribuídos de acordo com os grupos de participantes.

Gráfico 4 - Participantes das pesquisas de campo

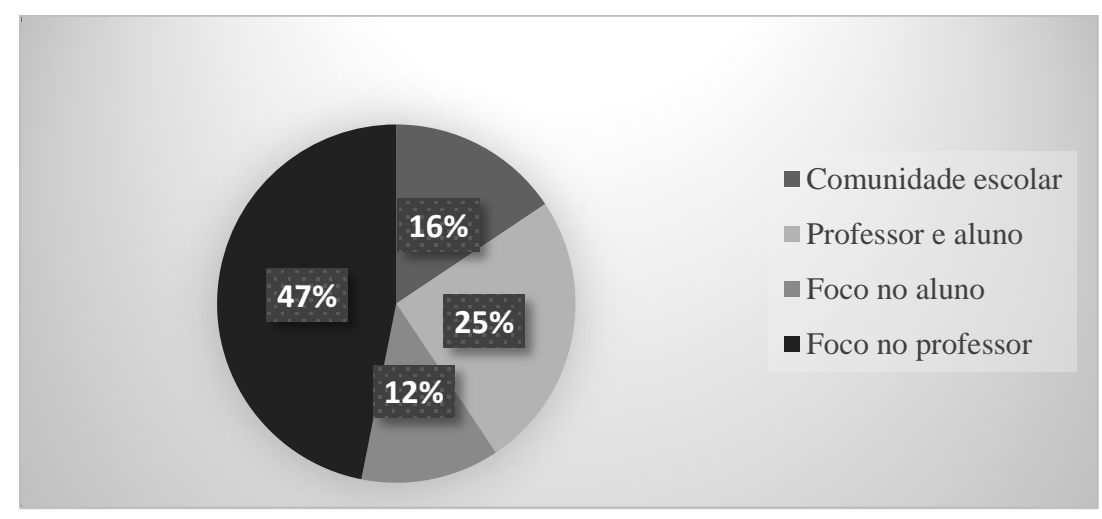

Fonte: Dados da pesquisa, elaborado pelos autores.

Os dados que emergiram da análise de dados apontam que grande parte da produção discente na área de Educação Física e Inclusão tem sido centrada no professor de Educação Física. Tais achados distanciam-se do estudo realizado por Manzini et al. (2006), que teve como objetivo resgatar e analisar as dissertações e as teses em Educação Especial do Programa de PósGraduação em Educação da UNESP de Marília. Os autores constataram que os professores, os alunos e a comunidade escolar eram as principais fontes de informação dos estudos realizados, o que foi considerado um aspecto positivo uma vez que esses estudos procuraram compreender a escola de uma forma abrangente. 
A centralidade no professor de Educação Física como principal respondente das pesquisas encontradas acaba por atribuir de forma indireta a responsabilidade do processo inclusivo à figura docente. Dessa forma, mesmo reconhecendo que esse profissional possui um papel determinante frente ao processo de Inclusão de estudantes com deficiências nas escolas, é necessário compreender que muitos requisitos (acessibilidade física, orientação aos familiares, recursos humanos de suporte, materiais adaptados, entre outros fatores) fogem à sua alçada (MACHADO, 2005). Diante do exposto, torna-se importante que as teses e as dissertações na área descentralizem o foco de pesquisa para além do professor de Educação Física, adotando uma visão mais sistêmica do processo.

Quanto às categorias de deficiências envolvidas nos estudos, o Gráfico 5 apresenta as 17 pesquisas cujo foco se baseou na díade aluno-professor ou somente no aluno. A seguir serão apresentadas as categorias de deficiência mais abordadas nas pesquisas de campo.

Gráfico 5 - Categorias de deficiência mais abordadas nas pesquisas de campo

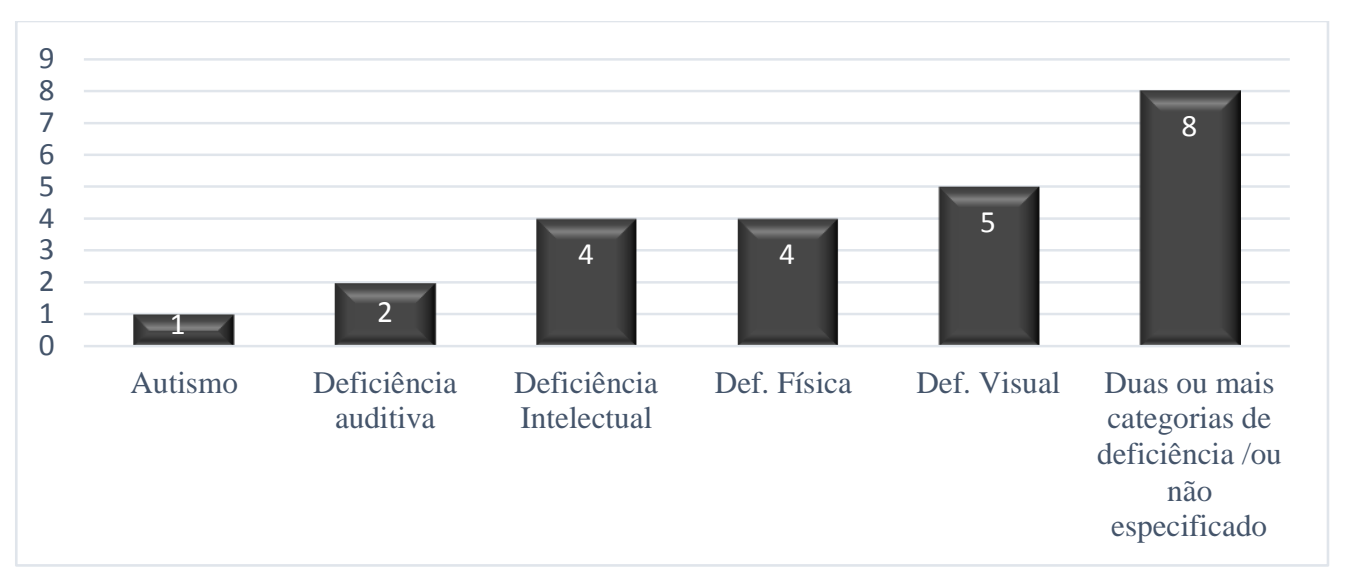

Fonte: Dados da pesquisa, elaborado pelos autores.

A maior parte das pesquisas de campo teve como população-alvo os estudantes com deficiência visual $(\mathrm{n}=5)$. Vários estudos $(\mathrm{n}=8)$ abordavam duas ou mais deficiências ou as tratava de forma genérica, não especificando os tipos de deficiência. Não foram encontradas pesquisas envolvendo alunos com Transtorno Global do Desenvolvimento (TGD), altas habilidades e/ou superdotação, deficiências múltiplas ou surdocegueira.

Assim, é possível verificar uma lacuna em relação à abordagem dessas categorias de deficiências nas pesquisas relacionadas à Inclusão no contexto da Educação Física escolar. Dessa forma, sugere-se que mais estudos sejam realizados com foco nos alunos com TGD, altas habilidades/superdotação, deficiências múltiplas, surdocegueira, autismo e deficiência auditiva.

\section{- Principais temáticas estudadas}

Os temas representam de forma geral os assuntos abordados nos documentos. Assim, as pesquisas foram organizadas em categorias temáticas definidas à posteriori a partir dos objetivos dos estudos. Para a classificação dos trabalhos em categorias, foram consideradas as seguintes definições para cada um dos temas: 


\section{- Prática pedagógica}

Enquadraram-se nessa categoria 15 estudos, três teses e 12 dissertações, que tinham como foco as ações ou as práticas pedagógicas empreendidas pelo professor de Educação Física em seu cotidiano escolar.

\section{- Análise do processo inclusivo}

Os trabalhos organizados nessa categoria $(n=15)$, duas teses e treze dissertações, de forma geral, tiveram como principal orientação de pesquisa a investigação e a análise de como o processo de Inclusão vêm ocorrendo no contexto das aulas de Educação Física escolar.

\section{- Formação continuada}

Foram enquadrados nessa categoria 12 trabalhos, sendo nove dissertações e três teses, que abordavam a formação continuada de professores de Educação Física com foco na Inclusão de crianças com deficiência, autismo e TGD. Assim, a categoria Formação Continuada englobou os estudos que tinham como tema central o processo de complementação de estudos ou cursos de Pós-Graduação em áreas específicas da Educação Física Inclusiva/ e ou Adaptada de longa ou curta duração.

\section{- Percepção, concepção e atitudes dos professores e /ou dos alunos sobre Inclusão}

Enquadraram-se nessa categoria os estudos de intenções, de concepções, de sentimentos e de atitudes a respeito dos significados, das práticas e das dificuldades acerca da Inclusão por professores de Educação Física, estudantes com deficiência e seus pares. Entre as dissertações e teses, doze pesquisas foram identificadas nessa categoria.

\section{- Estratégias de apoio à Inclusão}

Nessa categoria, foi encontrado um total de cinco estudos, três dissertações de Mestrado e duas teses de Doutorado. Enquadraram-se, nesse tema, as pesquisas envolvendo estratégias ou modelo de serviços de suporte ao processo de Inclusão escolar nas aulas de Educação Física. Foram compreendidos como estratégias de apoio os estudos sobre tutoria (colega tutor), ensino colaborativo e consultoria colaborativa, assim como os estudos relacionados ao suporte fornecido de forma geral ao professor ou à comunidade escolar que auxilie no processo de Inclusão.

\section{- Conteúdos curriculares}

Compreende-se por conteúdo curricular os elementos da Cultura Corporal de movimento abordados nas aulas de Educação Física escolar, os quais são: conhecimento sobre o corpo, esportes, jogos, lutas, ginásticas, atividades rítmicas e expressivas (BRASIL, 1998). Assim, nessa categoria, foram encontrados quatro estudos, sendo três dissertações de Mestrado e uma tese de Doutorado, todas caracterizadas como pesquisas de campo, as quais tinham como foco central o desenvolvimento de conteúdos inerentes à área de conhecimento da Educação Física escolar, como ferramenta/ meio para a promoção da Inclusão. 


\section{- Relação ou interação professor-aluno}

Pertencem a essa categoria os estudos sobre as interações e as relações entre professor aluno, e aluno com deficiência e sem deficiência estabelecidas no contexto das aulas de Educação Física escolar. Foram identificadas três dissertações, das quais duas foram desenvolvidas em Programas de Pós-Graduação na área de Psicologia.

\section{- Avaliação em Educação Física escolar e Inclusão}

Foram incluídas nessa categoria as pesquisas que abordavam a avaliação nas aulas de Educação Física escolar em contextos inclusivos. Assim, duas dissertações de Mestrado foram identificadas sob a temática.

\section{- Análise da produção teórica em Educação Física e Inclusão}

Foram englobados nessa categoria os estudos de análise de documentos públicos assim como os estudos de revisão de literatura. Quatro dissertações de Mestrado foram enquadradas nessa categoria.

\section{- Análise das políticas públicas em Educação Física e Inclusão}

Os estudos com base nessa temática debruçaram-se sobre a questão das políticas públicas envolvendo Educação Física e Inclusão. Uma única dissertação de Mestrado foi incluída nesse tema.

A seguir, no Gráfico 6, são apresentadas as categorias e a distribuição da produção discente por temática.

Gráfico 6 - Número de trabalhos por categoria temática

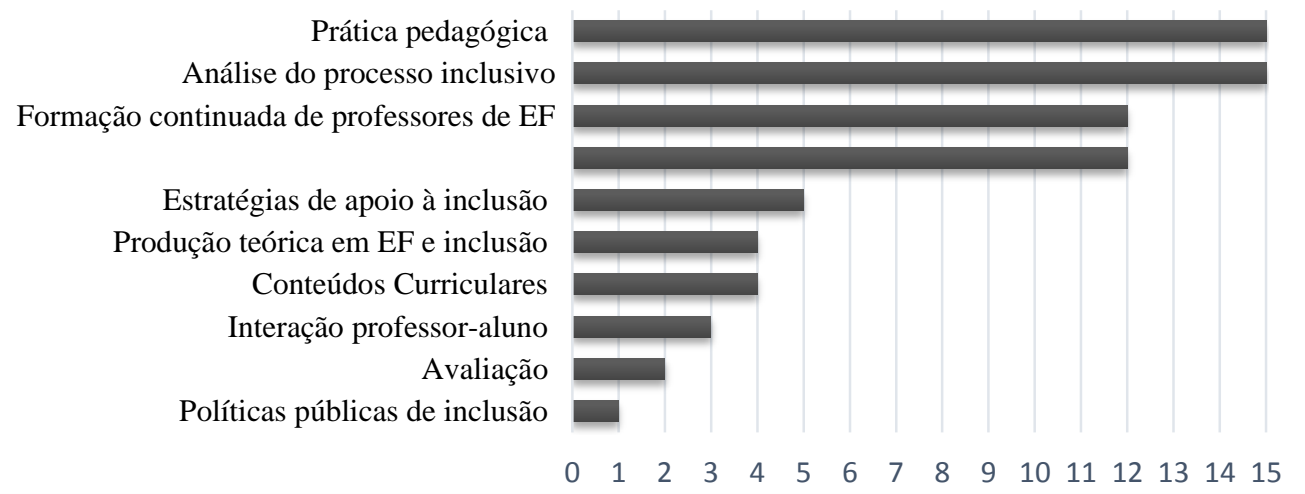

Fonte: Dados da pesquisa, elaborado pelos autores.

A maioria das pesquisas concentram-se em quatro principais temáticas, a saber: prática pedagógica; análise do processo inclusivo; formação continuada de professores de Educação Física; e percepção, concepção e atitudes dos professores e/ou dos alunos sobre Inclusão. Esses quatro temas representam cerca de $74 \%$ do total de estudos produzidos, apesar do significativo número de produções. De forma geral, os estudos pertencentes a essas temáticas acabam por não 
intervir diretamente no contexto escolar, permanecendo na perspectiva de análise e diagnóstico da realidade.

Tais resultados corroboram com os dados encontrados por Block e Obrusnikova (2007). Os autores concluem que o estudo das intenções e das atitudes por estudantes com deficiência e seus pares na comunidade escolar tem sido um tema recorrente nas pesquisas relacionadas à Inclusão escolar e à Educação Física em artigos de língua inglesa.

Em pesquisa de revisão de literatura internacional sobre Educação Física e Inclusão, desenvolvido por Qi e Há (2012), foi identificado que as principais temáticas estudadas nos artigos encontrados se referem às análises de práticas inclusivas eficazes e os impactos da Inclusão em estudantes com e sem deficiências.

Em relação às temáticas menos exploradas nos trabalhos incluídos no presente estudo, é possível destacar: estratégias de apoio à Inclusão; conteúdos curriculares; relação ou interação professor-aluno; avaliação em Educação Física e Inclusão escolar; análise da produção teórica em Educação Física e Inclusão escolar; e análise das políticas públicas em Educação Física e Inclusão.

Assim, no que diz respeito aos estudos de estratégias de apoio à Inclusão, ou seja, aos estudos propositivos ao fortalecimento de redes de apoio e criação de estratégias que possam dar suporte ao processo de Inclusão, eles ainda são escassos. $O$ mesmo pode ser destacado em relação às temáticas: avaliação, análise da produção teórica e análise das políticas públicas, que foram pouco abordadas no total de trabalhos encontrados. Dessa forma, embora as pesquisas realizadas tragam contribuições importantes para a reflexão do processo de Inclusão nas aulas de Educação Física escolar, o número reduzido em tais temáticas demonstraram ser um campo pouco explorado pelos pesquisadores, revelando lacunas na produção científica da área.

A partir do exposto, é possível verificar que a produção acadêmica em dissertações e teses brasileiras, que versam sobre a Inclusão escolar de estudantes com deficiências no contexto das aulas de Educação Física, vem se expandindo de forma significativa. Entretanto, as temáticas abordadas pela maioria das pesquisas permanecem na perspectiva diagnóstica e não têm ousado no sentido de propor temas que redirecionem, aprofundem ou ampliem as reflexões sobre o processo de Inclusão de alunos com deficiência nas aulas de Educação Física escolar. Nessa direção, para Mendes (2008, p. 19), no atual contexto das produções científicas sobre Inclusão, "[...] pesquisar muito já não é o suficiente; é preciso produzir conhecimento novo que responda as atuais demandas por informação".

Assim, de acordo com Maculan e Lima (2011), para que o pesquisador esteja preparado para novas descobertas, é importante que este possa utilizar os resultados de pesquisas já concluídas, o que evita a replicação de trabalhos e a duplicação de esforços. Dessa forma, em estudos futuros, sugere-se que sejam realizadas pesquisas que abordem as temáticas menos exploradas nas dissertações e teses produzidas até o momento, a fim de fornecer suporte teórico e prático aos desafios que se impõem no campo da Educação Física e Inclusão escolar do público-alvo da Educação Especial.

\section{Considerações finais}

A partir de um estudo de revisão sistemática, foram identificadas e analisadas 73 teses e dissertações sobre a temática Educação Física e Inclusão escolar produzidas nos programas de Pós-Graduação do Brasil entre os anos de 2002 a 2015. Além do mapeamento da produção

Práxis Educativa, Ponta Grossa, v. 12, n. 2, p. 570-590, maio/ago. 2017 Disponível em: <http://www.revistas2.uepg.br/index.php/praxiseducativa > 
científica, foi possível identificar o lócus de produção, a população participante dos estudos, as principais temáticas abordadas pelas pesquisas, assim como algumas áreas de estudo que têm sido negligenciadas e podem tornar-se alvo de futuras investigações.

Em relação ao lócus de produção, grande parte do conhecimento produzido na área advém de instituições públicas localizadas na região Sudeste do país, mais especificamente no estado de São Paulo. A partir do exposto, verifica-se a necessidade da descentralização da produção de conhecimento e o incentivo à produção científica nas demais regiões do país.

A maior parte das pesquisas envolvendo a interface Educação Física e Inclusão escolar tem sido centrada no professor de Educação Física. Os principais temas investigados têm sido a análise da prática pedagógica, a análise do processo inclusivo e a formação continuada desse profissional.

Embora tenha-se verificado o incremento no número de publicações, sobretudo na última década, observa-se a necessidade de adotar uma visão sistêmica, descentralizando o foco excessivo no processo de atuação e de formação do professor de Educação Física. É necessário estimular e aprofundar estudos que engendrem mudanças nas políticas públicas, direcionadas a serviços de apoio à Inclusão que forneça suporte à comunidade escolar e ao professor no processo de Inclusão, de forma a garantir atendimento especializado aos estudantes com deficiências voltadas especificamente ao contexto da Educação Física escolar.

Para concluir, o aumento dos estudos vinculados à temática Educação Física e Inclusão não necessariamente implica na superação das dificuldades identificadas e tampouco se traduz no avanço do discurso, das ações e das políticas que efetivamente possam dar suporte a novas formas de se pensar e intervir de forma inclusiva nesse âmbito.

\section{Referências}

BLOCK, M. E.; OBRUSNIKOVA, I. Inclusion in Physical Education: a review of the literature from 1995-2005. Adapted Physical Activity Quarterly, v. 24, n. 2, p. 103-124, 2007. DOI: 10.1123/apaq.24.2.103

BRASIL. Secretaria de Educação Fundamental. Parâmetros curriculares nacionais: Educação Física, $3^{\circ}$ e $4^{\circ}$ ciclos, v. 7. Brasília: MEC, 1998.

BRASIL. Ministério da Educação. Resolução CNE/CEB No 2, de 11 de setembro de 2001. Institui Diretrizes Nacionais para a Educação Especial na Educação Básica. Disponível em: <http://portal.mec.gov.br/cne/arquivos/pdf/CEB0201.pdf>. Acesso em: 28 de jan. 2017.

BRASIL. Ministério da Educação. Política Nacional de Educação Especial na perspectiva da Educação Inclusiva. Brasília: MEC; SEEP, 2008.

BRASIL. Ministério da Educação. Parecer CNE/CEB No 13/2009. Diretrizes Operacionais para o atendimento educacional especializado na Educação Básica, modalidade Educação Especial, 2009. Disponível em: $<$ http://portal.mec.gov.br/dmdocuments/pceb013_09_homolog.pdf $>$. Acesso em: 28 maio 2016. 
ERCOLE, F. F.; MELO, L. S.; ALCOFORADO, C. L. G. C. Integrative review versus systematic review. Reme: Revista Mineira de Enfermagem, Belo Horizonte, v. 18, n. 1, p. 911. 2014. DOI: $10.5935 / 1415-2762.20140001$

GOMES, I. S.; CAMINHA, I. O. Guia para estudos de revisão sistemática: uma opção metodológica para as Ciências do Movimento Humano. Movimento, Porto Alegre, v. 20, n. 1, p. 395-411, jan./mar. 2014.

JAMES, A. R.; LIEBERMAN, L. J.; LUDWA, N. The impact of inclusion in general Physical Education for all students. Journal of Physical Education, Recreation \& Dance, v. 75, n. 5, p. 37-41, may./jun. 2004. DOI: 10.1080/07303084.2004.10607238

MACHADO, K. S. A prática da Inclusão de alunos com necessidades educativas especiais em classe regular: um estudo de caso com abordagem etnográfica. 2005. 106 f. Dissertação (Mestrado em Educação) - Faculdade de Educação, Universidade do Estado do Rio de Janeiro, Rio de Janeiro, 2005.

MACULAN, B. C. M. S.; LIMA, G. A. B. O modelo para análise conceitual de teses e dissertações com vistas à criação de taxonomia facetada. Informação \& Sociedade: estudos, v. 21, n. 3, p. 41-54, set./dez. 2011.

MAHL, E.; MUNSTER M. A. Análise das Dissertações e Teses do PPGEES/UFSCar na Interface Educação Física e Educação Especial. Revista Brasileira de Educação Especial, Rio de Janeiro, v. 21, n. 2, p. 299-318, abr./jun. 2015. DOI: 10.1590/s1413-65382115000200010

MANOEL, E. J.; CARVALHO, Y. M. Pós-graduação na educação física brasileira: a atração (fatal) para a biodinâmica. Educação e Pesquisa, São Paulo, v. 37, n. 2, p. 389-406, maio/ago. 2011. DOI: $10.1590 /$ s1517-97022011000200012

MANZINI, E. J. et al. Análise de dissertações e teses em educação especial produzidas no Programa de Pós-Graduação em Educação da UNESP - Marília (1993-2004). Revista Educação Especial, Santa Maria, n. 28, 2006.

MENDES, E. G. Pesquisas sobre Inclusão escolar: revisão da agenda de um grupo de pesquisa. Revista Eletrônica de Educação, São Carlos, v. 2, n. 1, p. 3-25, 2008. DOI: 10.14244/\%251982719911

MOHER, D. et al. Preferred reporting items for systematic reviews and meta-analyses: The PRISMA Statement. Annals of Internal Medicine, v. 151, n. 4, p. 264, ago. 2009. DOI: 10.7326/0003-4819-151-4-200908180-00135

MORAES, R. Análise de conteúdo. Revista Educação, Porto Alegre, v. 22, n. 37, p. 7-32, 1999.

NUNES, L. R. O. P.; FERREIRA, J. R.; MENDES, E. G. Produção discente da pós-graduação em educação e psicologia sobre o indivíduo com necessidades educacionais especiais. In: MENDES, E. G.; ALMEIDA, M. A.; WILliAMS, L. C. A. (Orgs.). Temas em Educação Especial: avanços recentes. São Carlos: EdUFSCar, 2004. p.131-142. 
QI, J.; HÁ, A. S. Inclusion in Physical Education: a review of literature. International Journal of Disability, Development and Education, v. 59, n. 3, p. 257-281, 2012. DOI: 10.1080/1034912x.2012.697737

SACARDO, M. S. Publicação científica derivada das dissertações e teses na interface entre educação física e educação especial. 2006. 134 f. Dissertação (Mestrado em Educação Especial) - Universidade Federal de São Carlos, São Carlos, 2006.

STEINER, J. E. Qualidade e diversidade institucional na Pós-Graduação brasileira. Estudos Avançados, São Paulo, v. 19, n. 54, p. 341- 362, maio/ago. 2005. DOI: 10.1590/s010340142005000200019

Recebido em 31/05/2016

Versão corrigida recebida em 20/02/2017

Aceito em 23/02/2017 